\title{
Allergen-Induced Asthmatic Responses Modified by a GATA3-Specific DNAzyme
}

\author{
Norbert Krug, M.D., Jens M. Hohlfeld, M.D., Anne-Marie Kirsten, M.D., \\ Oliver Kornmann, M.D., Kai M. Beeh, M.D., Dominik Kappeler, M.D., \\ Stephanie Korn, M.D., Stanislav Ignatenko, M.D., Wolfgang Timmer, M.D., \\ Cordelia Rogon, Dipl.-Stat., Jana Zeitvogel, Ph.D., Nan Zhang, M.D., Ph.D., \\ Joachim Bille, Ph.D., Ursula Homburg, M.Sc., Agnieszka Turowska, Ph.D., \\ Claus Bachert, M.D., Ph.D., Thomas Werfel, M.D., Roland Buhl, M.D., \\ Jonas Renz, M.A., Holger Garn, Ph.D., and Harald Renz, M.D.
}

A BSTRACT

BACKGROUND

The most prevalent phenotype of asthma is characterized by eosinophil-dominated inflammation that is driven by a type 2 helper T cell (Th2). Therapeutic targeting of GATA3, an important transcription factor of the Th2 pathway, may be beneficial. We evaluated the safety and efficacy of SB010, a novel DNA enzyme (DNAzyme) that is able to cleave and inactivate GATA3 messenger RNA (mRNA).

\section{METHODS}

We conducted a randomized, double-blind, placebo-controlled, multicenter clinical trial of SB010 involving patients who had allergic asthma with sputum eosinophilia and who also had biphasic early and late asthmatic responses after laboratory-based allergen provocation. A total of 40 patients could be evaluated; 21 were assigned to receive $10 \mathrm{mg}$ of SB010, and 19 were assigned to receive placebo, with each study drug administered by means of inhalation once daily for 28 days. An allergen challenge was performed before and after the 28-day period. The primary end point was the late asthmatic response as quantified by the change in the area under the curve (AUC) for forced expiratory volume in 1 second $\left(\mathrm{FEV}_{1}\right)$.

RESULTS

After 28 days, SB010 attenuated the mean late asthmatic response by 34\%, as compared with the baseline response, according to the AUC for $\mathrm{FEV}_{1}$, whereas placebo was associated with a $1 \%$ increase in the AUC for $\mathrm{FEV}_{1}(\mathrm{P}=0.02)$. The early asthmatic response with SB010 was attenuated by $11 \%$ as measured by the AUC for $\mathrm{FEV}_{1}$, whereas the early response with placebo was increased by $10 \%(\mathrm{P}=0.03)$. Inhibition of the late asthmatic response by SB010 was associated with attenuation of allergeninduced sputum eosinophilia and with lower levels of tryptase in sputum and lower plasma levels of interleukin-5. Allergen-induced levels of fractional exhaled nitric oxide and airway hyperresponsiveness to methacholine were not affected by either SB010 or placebo.

\section{CONCLUSIONS}

Treatment with SB010 significantly attenuated both late and early asthmatic responses after allergen provocation in patients with allergic asthma. Biomarker analysis showed an attenuation of Th2-regulated inflammatory responses. (Funded by Sterna Biologicals and the German Federal Ministry of Education and Research; ClinicalTrials.gov number, NCT01743768.)
From the Fraunhofer Institute for Toxicology and Experimental Medicine (N.K., J.M.H.) and the Department of Dermatology and Allergy, Hannover Medical School (J.Z., T.W.), Hannover, Pulmonary Research Institute at Lung Clinic Grosshansdorf, Grosshansdorf (A.-M.K.), Institut für klinische Forschung Pneumologie, Clinical Research Center Respiratory Medicine, Frankfurt (O.K.), Insaf Respiratory Research Institute, Wiesbaden (K.M.B.), Inamed, Gauting (D.K., W.T.), Pulmonary Department, Medical Clinic, University Hospital Mainz, Mainz (S.K., R.B.), Charité Research Organization, Berlin (S.I.), FGK Clinical Research, Munich (C.R.), Sterna Biologicals (J.B., U.H., A.T., J.R.) and Institute of Laboratory Medicine, Philipps University Marburg, a member of Universities Giessen and Marburg Lung Center (H.G., H.R.), Marburg - all in Germany; Upper Airways Research Laboratory, University Hospital Ghent, Ghent, Belgium (N.Z., C.B.); and the Division of Ear, Nose, and Throat Diseases, Clintec, Karolinska Institute, Stockholm (N.Z., C.B.). Address reprint requests to Dr. Renz at the Institute of Laboratory Medicine, Philipps University Marburg, Baldinger Str., 35043 Marburg, Germany, or at harald.renz@uk-gm.de.

Drs. Garn and Renz contributed equally to this article.

This article was published on May 17, 2015, at NEJM.org.

DOI: 10.1056/NEJMoa1411776

Copyright (๐) 2015 Massachusetts Medical Society. 
STHMA IS A COMMON CHRONIC INflammatory disease of the airways that is characterized by variable airway obstruction, hypersecretion of mucus, airway inflammation, and hyperresponsiveness of the airways. The dysregulation of innate and adaptive immune responses is considered to play a central role in the development of the disease. The high degree of interindividual heterogeneity identified in different patient populations has led to the definition of several clinical phenotypes and pathophysiological endotypes. ${ }^{1}$ The allergic response driven by the type 2 helper T cell (Th2), ${ }^{2,3}$ also termed the Th2 molecular endotype, is thought to be characteristic of allergic asthma., ${ }^{4,5}$

Approximately half the patients with asthma, regardless of the severity of the disease, exhibit this Th2 endotype. The endotype is characterized by a predominant activation of Th2 cells that produce cytokines such as interleukins 4, 5, and 13. The expression and production of all these Th2 cytokines have been shown in isolated cell systems and invertebrates to be controlled by the zinc finger transcription factor GATA3, which is essential for Th2-cell differentiation and activation and is considered to be the master transcription factor of the Th2 pathway of immune activation. ${ }^{6}$ The overexpression of GATA3 has been observed in specimens from bronchoalveolar lavage and lung biopsies obtained from patients with severe asthma, even when they are receiving intensive therapy. $^{7}$ Thus, interventions that can disrupt this immune network - including treatments targeting components downstream of the transcription factor GATA3 - are being developed for the treatment of asthma. ${ }^{8}$

Since GATA3 is expressed only in intracellular processes, we developed a GATA3-specific DNA enzyme (DNAzyme) with in vivo cell-penetrating capabilities. DNAzymes are catalytically active, single-stranded, synthetic DNA antisense molecules that do not occur in nature. The DNAzyme hgd40 - the active drug product in SB010 consists of 34 bases. Nine bases each at the $3^{\prime}$ and $5^{\prime}$ region form two binding domains that are highly specific for binding the target messenger RNA (mRNA) of GATA3. The central core of the molecule represents the catalytic domain that accounts for the cleavage of the target after the binding of hgd40 to GATA3 mRNA ${ }^{9,10}$ (Fig. S1 and S2 in the Supplementary Appendix, available with the full text of this article at NEJM.org). The hgd40 enzyme has shown efficacy in preclinical mod- els of allergic airway inflammation and has significantly reduced levels of both GATA3 mRNA and protein and, subsequently, the production of Th2 cytokines in human $\mathrm{T}$ cells and tissue explants ${ }^{11,12}$ (Fig. S3 in the Supplementary Appendix). Since unwanted, off-target effects have not been noted ${ }^{13,14}$ and since no major safety concerns were identified in three recently completed randomized, placebo-controlled, dose-escalation phase 1 trials, ${ }^{15}$ we conducted this phase $2 \mathrm{a}$ trial to assess the efficacy of SB010.

METHODS

STUDY DESIGN AND OVERSIGHT

We conducted this randomized, double-blind, placebo-controlled trial between January 2013 (first patient enrolled) and October 2013 (last visit by last patient) at seven sites in Germany that specialize in respiratory research. After patient screening and baseline assessments were performed, participants were assigned to receive active treatment or placebo for 4 weeks. Randomization was performed at Inamed with the use of a centrally generated list and with no stratification. Details of the study design are shown in Figure 1 and the protocol (available with the statistical analysis plan at NEJM.org). The trial was approved by the German regulatory agency Bundesinstitut für Arzneimittel und Medizinprodukte, by a central ethics committee, and by the local ethics committee at each participating site and was conducted according to the principles of the Declaration of Helsinki and the International Conference on Harmonisation Good Clinical Practice guidelines. All participants provided written informed consent before any study-specific procedures were performed. Data were collected at each study site and entered into a database at Inamed. The statistical analysis was performed independently by FGK Clinical Research. The first draft of the manuscript was prepared by the first and last authors. A professional medical writer funded by Sterna Biologicals provided writing and editorial support. The first and last authors and the authors employed by the sponsor vouch for the accuracy and completeness of the data, the statistical analysis, and the fidelity of the trial to the final protocol.

\section{PATIENTS}

We recruited white male patients between 18 and 64 years of age who had received a diagnosis of mild asthma, according to criteria in the guide- 
Figure 1. Study Design and Screening and

Randomization.

Panel A shows an overview of the study design and procedures. Panel B summarizes screening and randomization. In the SBO10 group, 21 patients completed all the study assessments; 1 patient was not eligible for evaluation because the dose of allergen administered in the pretreatment allergen challenge (AC) differed from that administered in the post-treatment AC. In the placebo group, 19 patients completed all the study assessments; 2 patients were not eligible for evaluation ( 1 patient required treatment with a short-acting beta-agonist during the $A C$, and 1 patient was administered a dose in the pretreatment $A C$ that differed from the dose administered in the post-treatment $A C)$. In the placebo group, the data for late asthmatic response (LAR) were missing for 1 patient because serial spirometry was unintentionally stopped 4 hours after allergen provocation. FENO denotes the fraction of nitric oxide in exhaled air, $\mathrm{FEV}_{1}$ forced expiratory volume in 1 second, IS induced sputum, MCh methacholine challenge, and $\mathrm{R}$ randomization.

lines from the Global Initiative for Asthma, ${ }^{16}$ at least 6 months before screening and who had not received treatment with any asthma medication other than inhaled short-acting bronchodilators. If a patient had been receiving treatment with inhaled glucocorticoids, the medications were stopped at least 2 weeks before the screening visit. At the screening visit, the forced expiratory volume in 1 second $\left(\mathrm{FEV}_{1}\right)$ had to be $70 \%$ or more of the predicted normal value for at least 6 hours after any use of a short-acting bronchodilator. The allergic nature of the asthma had to be confirmed by means of a positive response to common aeroallergens on a skin-prick test and an allergeninduced decline in $\mathrm{FEV}_{1}$ of $20 \%$ or more in the early asthmatic response and $15 \%$ or more in the late asthmatic response. The presence of sputum eosinophils (at least 1 in 400 counted cells) had to be confirmed either before or after the allergen challenge conducted at screening. The full details of the criteria for study inclusion and exclusion are provided in the protocol.

\section{TREATMENT}

The active product in SB010 is the GATA3-specific DNAzyme hgd40 (BioSpring); sequencing details for hgd40 are shown in Figure S4 in the Supplementary Appendix. The final drug product and the placebo were prepared at one site in identical packaging by BAG Health Care. Patients received $10 \mathrm{mg}$ of SB010 in $2 \mathrm{ml}$ of phosphate-buffered

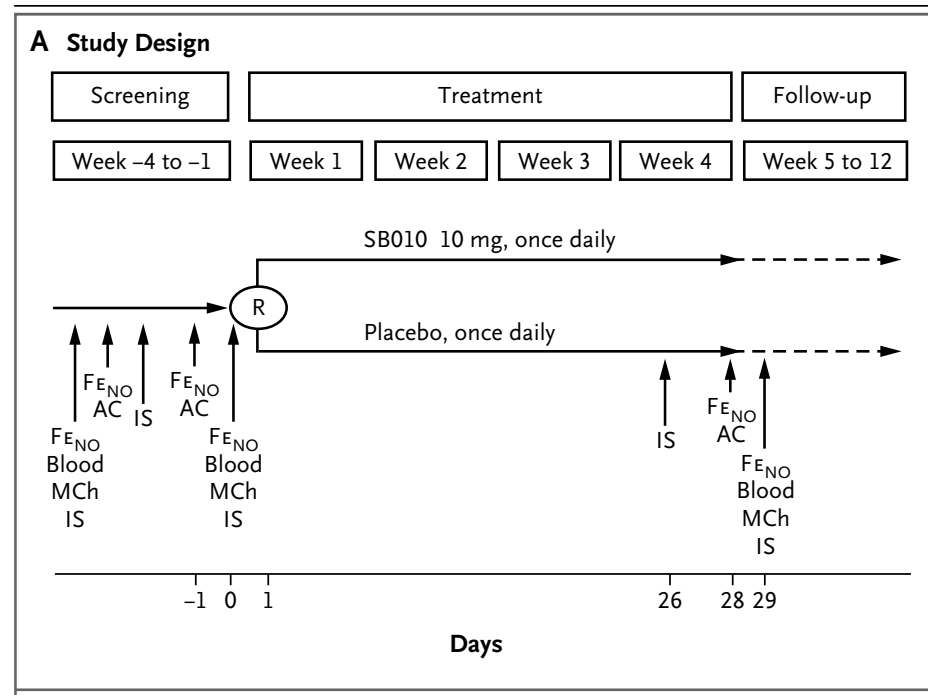

B Screening and Randomization

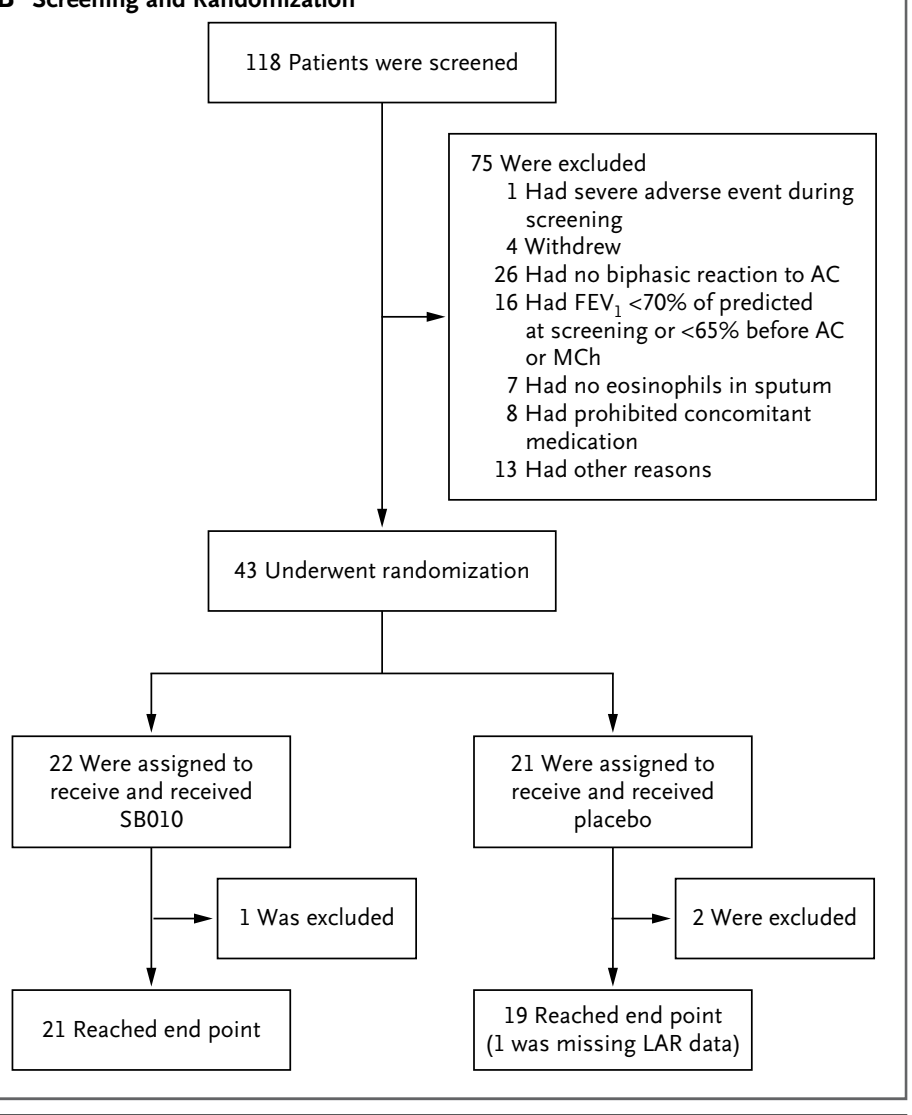

saline or matching placebo once daily for 28 consecutive days; both study drugs were administered in the morning by means of flow- and volume-controlled inhalation for a duration of 3 to 8 minutes with the use of an Akita ${ }^{2}$ Apixneb nebulizer (Activaero). ${ }^{17}$ Patients administered the active treatment or placebo at a study site under the supervision of the study staff on days $1,7,13$, 
20,26 , and 28 . On the remaining days, the product was self-administered by the study patients, who had been trained to inhale from the device (with a placebo inhalant) at the screening visit.

\section{PROCEDURES}

After a safe starting concentration had been identified ${ }^{18}$ increasing concentrations of inhaled aeroallergen were administered at the screening visit to determine the inhaled-aeroallergen regimen that would be used during the treatment phase. ${ }^{19}$ Inhaled-allergen challenges were administered in the identical manner before randomization (pretreatment) and after the 28-day study period (posttreatment)..$^{20}$ Serial spirometric measurements were performed repeatedly in accordance with recent guidelines. ${ }^{21}$ Appropriate washout times between challenges were implemented. An overview of the main study procedures and the interventions is shown in Figure 1A (a full summary of study procedures can be found in the study protocol).

\section{ASSESSMENTS}

A methacholine challenge was used to assess airway responsiveness at the times indicated in Figure 1A. Responsiveness was determined on the basis of the provocative concentration of methacholine required to reduce the $\mathrm{FEV}_{1}$ by at least $20 \%$ (methacholine $\mathrm{PC}_{20}$ ). The challenges were conducted in accordance with the guidelines of the American Thoracic Society (ATS). ${ }^{22}$ Levels of fractional exhaled nitric oxide $\left(\mathrm{Fe}_{\mathrm{NO}}\right)$ were measured at the times indicated in Figure $1 \mathrm{~A}$ with the use of a hand-held device (NIOX MINO, Aerocrine) in accordance with the recommendations of the ATS and the European Respiratory Society $^{23}$ and the manufacturer's instructions. Induced sputum samples were obtained at five time points (Fig. 1A): at screening, up to 2 weeks before the pretreatment challenge, 24 hours after the pretreatment challenge, 24 to 48 hours before the post-treatment challenge, and 24 hours after the post-treatment challenge. Assessment of cell distribution and analysis of mediators in the supernatant were performed at a central laboratory. ${ }^{24}$ Cytokines and chemokines were measured with a type 1 helper T-cell (Th1) and Th2 assay and a chemokine multiplex assay. The tryptase level in sputum supernatants was measured with the use of an enzyme-linked immunosorbent assay.

Adverse events and any medications prescribed in relation to such an event were assessed at every visit with the use of open questions. Laboratory analyses (e.g., measurement of hematologic and clinical chemistry values and urinalysis) were performed before the first administration of SB010 or placebo and at 2-week intervals during the study period.

\section{OUTCOME MEASURES}

The primary outcome measure was the area under the curve (AUC) for $\mathrm{FEV}_{1}$, expressed as a percentage of the baseline $\mathrm{FEV}_{1}$ during late asthmatic response (4 to 7 hours after allergen challenge), after administration of multiple doses of inhaled SB010. Secondary outcomes were the safety and side-effect profile of SB010, as assessed by evaluation of adverse events, vital signs, electrocardiographic findings, laboratory analyses, and tests of pulmonary function. Exploratory end points included the AUC for $\mathrm{FEV}_{1}$ during early asthmatic response ( 0 to 3 hours after allergen challenge), allergen-induced changes in airway responsiveness (methacholine $\mathrm{PC}_{20}$ ), and changes in $\mathrm{FE}_{\mathrm{NO}}$ and in biomarker levels in plasma and sputum after treatment with SB010.

\section{STATISTICAL ANALYSIS}

We calculated that for the study to have at least $80 \%$ power to detect a between-group difference in effect size of $8 \%$ for the change in the AUC during the late-phase asthmatic response (percent change in $\mathrm{FEV}_{1} \times$ no. of hours), a sample of at least 38 participants who could be evaluated would be required, assuming a probability of type I error of $10 \%$. On the basis of an anticipated dropout rate of 15\%, 43 patients were randomly assigned to receive SB010 or placebo. Efficacy and pharmacodynamic outcomes were analyzed for all patients who could be evaluated (intention-to-treat population), as indicated in Figure 1.

The primary efficacy outcome (AUC for late asthmatic response) was compared between treatment groups with the use of an analysis-of-covariance (ANCOVA) model, with the baseline AUC in the late asthmatic response used as the covariate. The calculation of the AUC was based on the percentage of baseline $\mathrm{FEV}_{1}$ over time with the use of the trapezoidal rule, as detailed in the statistical analysis plan in the protocol. Four patients in the SB010 group and three patients in the placebo group had a late asthmatic response only in the first pretreatment allergen challenge. 


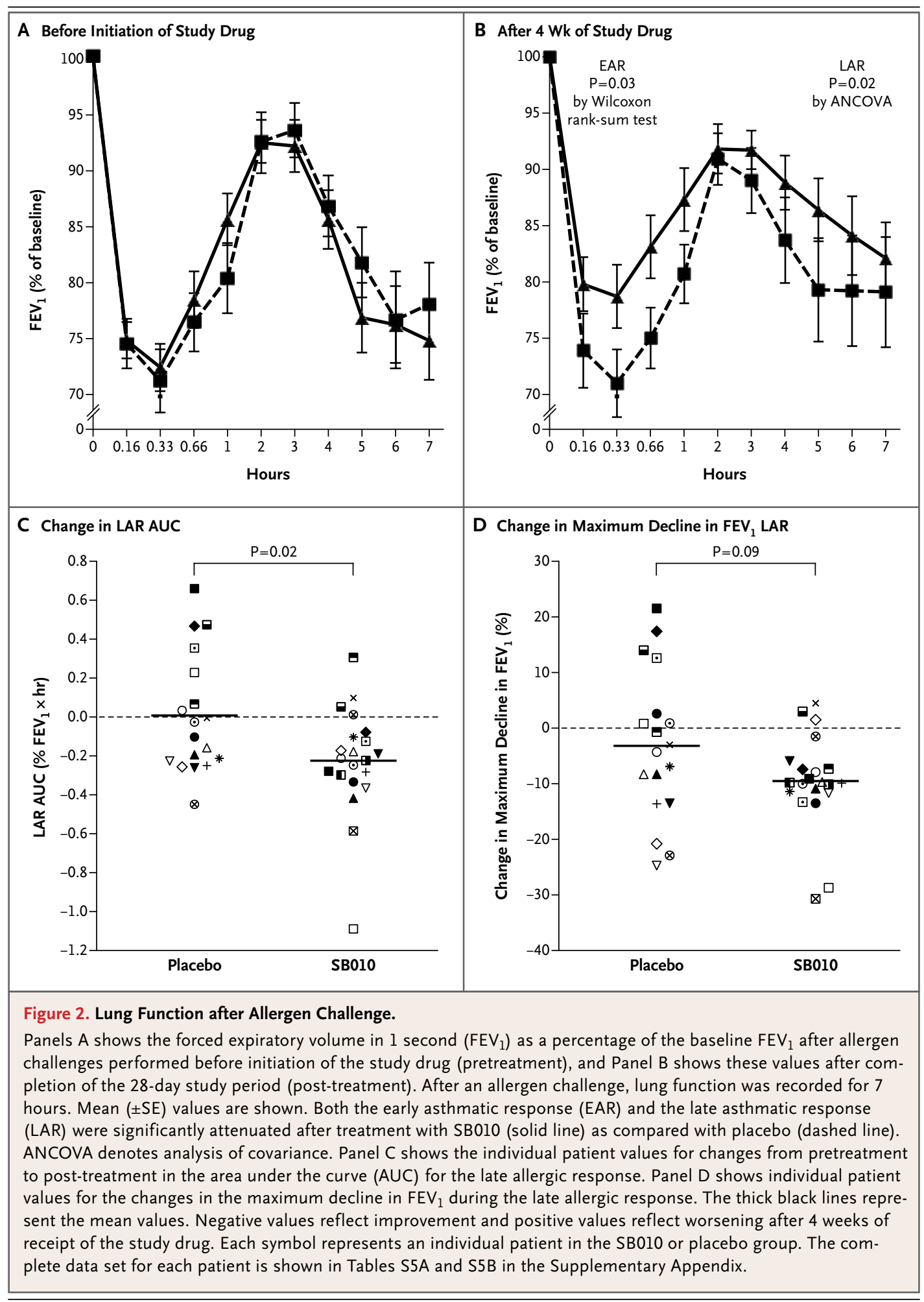

For these patients, data on lung function from this challenge were used as the pretreatment value; for all other patients, the baseline value was the re- sponse to the second allergen challenge performed immediately before treatment. Other end points were also analyzed with the use of the same 


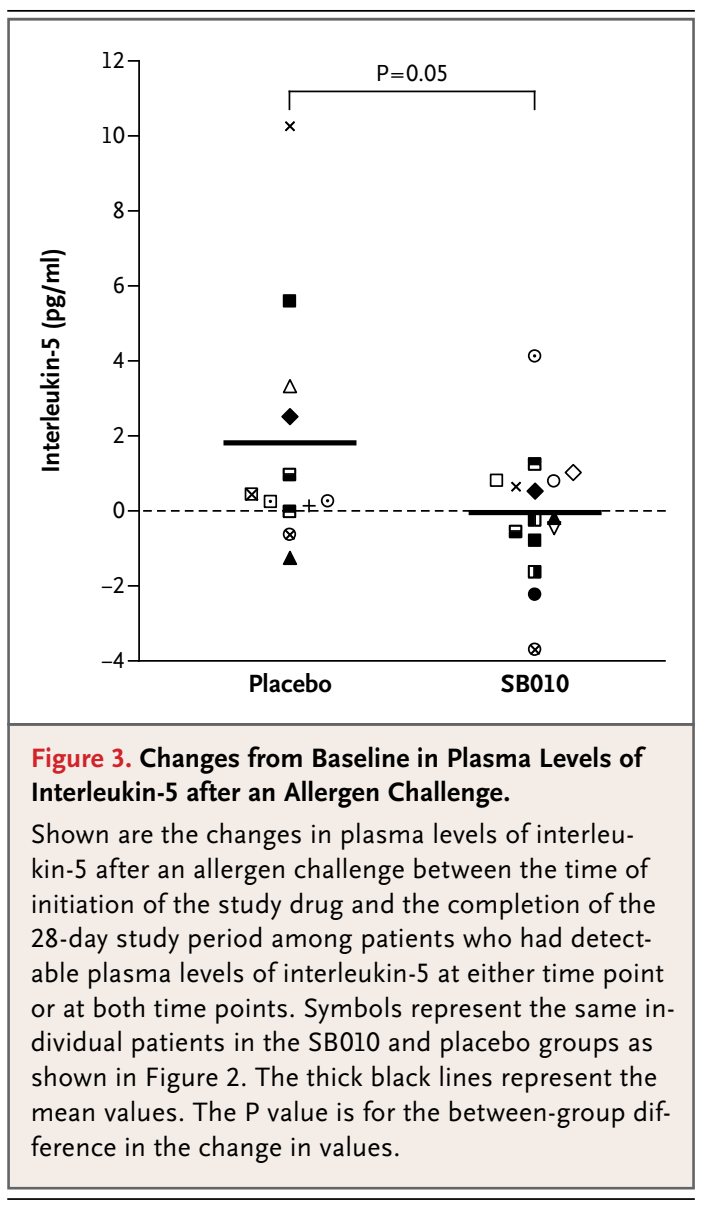

model or with Wilcoxon rank-sum tests. Safety outcome measures were listed according to patient, and descriptive statistics were calculated. Further details on the statistical methods are provided in the protocol.

\section{RESULTS}

\section{PATIENTS}

In the SB010 group, 21 patients completed all the study assessments; in the placebo group, 18 completed the assessment of late asthmatic response and 19 completed the assessment of early asthmatic response (Fig. 1B). The demographic and baseline data for these patients are shown in Table S2 in the Supplementary Appendix.

\section{LATE- AND EARLY-PHASE RESPONSES}

As shown in Figure 2 (and Tables S3 and S4 in the Supplementary Appendix), the late asthmatic response was attenuated after treatment with SB010, and there was a significant improvement (i.e., decrease) in the mean AUC from the pretreatment to the post-treatment allergen challenge, from 66.4 to 44.0 (percent $\mathrm{FEV}_{1} \times$ hours $\times 100$ ), reflecting a decrease of $33.7 \%$ (as compared with a worsening [i.e., increase] of $1.4 \%$ in the placebo group) $(\mathrm{P}=0.02)$, and an improvement (i.e., decrease) in the maximum decline in $\mathrm{FEV}_{1}$ from $30.1 \%$ to $20.6 \%$, reflecting a decrease of $31.6 \%(\mathrm{P}=0.09)$. The early asthmatic response was also attenuated, with a significant improvement in the mean AUC from 37.9 to 33.6, reflecting a mean improvement in the AUC of $11.3 \%$ (as compared with a worsening of $10.5 \%$ in the placebo group) $(\mathrm{P}=0.03)$, and an improvement in the maximum decline in $\mathrm{FEV}_{1}$ from $30.3 \%$ to $23.8 \%$, reflecting a decrease of 21.5\% ( $\mathrm{P}=0.04)$ (Fig. 2, and Tables S3 and S4 in the Supplementary Appendix). Data for individual patients are listed in the Tables S5A and S5B in the Supplementary Appendix

\section{INTERFERENCE WITH MARKERS OF TH2-DRIVEN INFLAMMATION}

After 28 days of treatment, SB010 attenuated the allergen-induced increase in sputum eosinophilia as compared with placebo, although this difference was not significant $(\mathrm{P}=0.06)$ There was, however, a significant change in levels of blood interleukin-5 $(\mathrm{P}=0.05)$ (Fig. 3). The post-treatment increase in interleukin-5 levels observed in the placebo group was not observed in the group receiving SB010. At the end of the 28-day study period, sputum tryptase levels were significantly lower in the SB010 group than in the placebo group (median, 6.39 ng per milliliter [interquartile range, 2.03 to 13.88 ] vs. median, $13.10 \mathrm{ng}$ per milliliter [interquartile range, 6.05 to 22.77 ]; $\mathrm{P}=0.05$ ). Allergen-induced levels of $\mathrm{F}_{\mathrm{NO}}$ and airway hyperresponsiveness to methacholine remained unaffected by either SB010 or placebo 24 hours after the challenge (Table S8 in the Supplementary Appendix).

\section{SAFETY AND ADVERSE EVENTS}

No noteworthy differences in adverse events were observed between patients receiving SB010 and those receiving placebo during the 28-day study period. Eight patients in the placebo group, as compared with six patients in the SB010 group, had an adverse event (Table 1). There were no serious adverse events during the study period. 


\begin{tabular}{|c|c|c|c|c|c|}
\hline \multirow[t]{3}{*}{ Organ System } & \multirow[t]{3}{*}{ Specific Events } & \multicolumn{2}{|c|}{ SB010 ( $N=22)$} & \multicolumn{2}{|c|}{ Placebo $(\mathrm{N}=21)$} \\
\hline & & $\begin{array}{l}\text { No. of } \\
\text { Events }\end{array}$ & $\begin{array}{l}\text { Patients } \\
\text { with Event }\end{array}$ & $\begin{array}{l}\text { No. of } \\
\text { Events }\end{array}$ & $\begin{array}{l}\text { Patients } \\
\text { with Event }\end{array}$ \\
\hline & & & no. (\%) & & no. (\%) \\
\hline Ear and labyrinth disorders & Vertigo & 1 & $1(5)$ & 0 & 0 \\
\hline Gastrointestinal disorders & Diarrhea, nausea & 1 & $1(5)$ & 1 & $1(5)$ \\
\hline Infections and infestations & Herpes simplex, nasopharyngitis & 4 & $3(14)$ & 2 & $2(10)$ \\
\hline $\begin{array}{l}\text { Injury, poisoning, and procedural } \\
\text { complications }\end{array}$ & Laceration & 0 & 0 & 1 & $1(5)$ \\
\hline $\begin{array}{l}\text { Musculoskeletal and connective-tissue } \\
\text { disorders }\end{array}$ & Myalgia & 1 & $1(5)$ & 0 & 0 \\
\hline Nervous system disorders & Headache, sciatica & 5 & $3(14)$ & 2 & $2(10)$ \\
\hline $\begin{array}{l}\text { Respiratory, thoracic and mediastinal } \\
\text { disorders }\end{array}$ & $\begin{array}{l}\text { Asthma, bronchial obstruction, } \\
\text { dyspnea, increased upper-air- } \\
\text { way secretion, oropharyngeal } \\
\text { pain, upper-airway cough syn- } \\
\text { drome }\end{array}$ & 3 & $3(14)$ & 5 & $4(19)$ \\
\hline Skin and subcutaneous tissue disorders & Pruritus & 1 & $1(5)$ & 0 & 0 \\
\hline
\end{tabular}

The analysis of safety end points did not reveal any safety concerns. There were no significant between-group differences in pretreatment and posttreatment levels of TNF- $\alpha$, interleukins $1 \beta$ and 8 , monocyte chemotactic proteins 1 and 4 , macrophage inflammatory protein $1 \beta$, macrophagederived chemokine, and interferon-inducible protein 10 (Table S7 in the Supplementary Appendix). No significant increases in levels of rheumatoid factor or antinuclear antibodies were detected in either group.

\section{DISCUSSION}

The inhaled bronchial allergen challenge is a widely accepted in vivo model for the observation of allergic inflammation and bronchoconstriction. ${ }^{19,25}$ All new therapeutic approaches targeting pathways of Th2 cytokines, such as interleukin-4, ${ }^{26-28}$ interleukin-5, ${ }^{29-31}$ interleukin-13, ${ }^{32,33}$ and thymic stromal lymphopoietin (TSLP), ${ }^{34}$ which are now in later stages of development, were successful in attenuating the late asthmatic response in early clinical trials. In this study, treatment with SB010 significantly improved lung function during both early and late asthmatic responses after allergen inhalation. Since SB010 specifically and selectively targets the transcription factor GATA3, these data strongly support the importance of GATA3-dependent and regulated pathways in the asthmatic response after allergen inhalation in patients with a phenotype for Th2-driven asthma. ${ }^{6}$

The patients in our study had mild allergic asthma with a typical Th2-driven endotype, as indicated by elevated levels of eosinophils in blood and sputum and elevated levels of $\mathrm{FE}_{\mathrm{NO}} \cdot{ }^{35,36}$ This type-2 endotype not only is present in prototypical atopic and allergic asthma but also has recently been observed in other clinical phenotypes of asthma, including hypereosinophilic late-onset asthma, persistent and severe asthma, and aspirin-sensitive asthma. ${ }^{5,37,38}$ The criteria for inclusion in the study were designed to cover a broad spectrum of patients with this endotype (e.g., requiring only the "presence of sputum eosinophils"), and the data on lung function showed that SB010 had a significant effect in this population. SB010 had a more pronounced attenuating effect on the late asthmatic response, but there was also significant attenuation in the early asthmatic response. This dual mode of action across both phases of the asthmatic response has been reported for anti-IgE ${ }^{39}$ and anti-TSLP ${ }^{34}$ but not inhaled glucocorticoids. ${ }^{40}$

The central role of GATA3 in the regulation of the Th2 response is well established. Both the 
development and the maintenance of Th2-effector functions have been shown to depend strictly on GATA3.$^{41}$ More recently, investigators have identified an essential function of GATA3 in type 2 innate lymphoid cells. ${ }^{42}$ However, this transcription factor also has important functions that extend well beyond its effects on the Th2-cell subset. GATA3 is also expressed in mast cells ${ }^{41}$ eosinophils, ${ }^{43}$ and airway epithelial cells, where it controls type 2 cytokine expression and effector mechanisms associated with the allergen-induced allergic response. ${ }^{44,45}$ After an allergen challenge, the early asthmatic response depends on mast-cell degranulation, whereas the late asthmatic response is considered to be preferentially T-cell dependent and accompanied by a marked influx of eosinophils into the airways and the airway lumen. Mast-cell tryptase represents a reliable and robust marker of mast-cell activation and mast-cell degranulation. Our results indicate that SB010 directly or indirectly affects these effector cells of the asthmatic response after allergen inhalation. It is likely that SB010 performs this inhibitory and modulatory function in a dual fashion, both by modulating Th2 cells, and thus depriving effector cells of survival and activation factors, and by directly interfering with GATA3 mRNA in eosinophils and mast-cells in the local inflamed tissue. Additional mechanistic studies are needed to further elucidate the biologic effects of treatment with a GATA3-specific DNAzyme. In our small study, one patient in the SB010 group had nausea and one had pruritus. Our database is too small to draw any conclusions about the long-term safety of this treatment, especially in regard to infectious events.

In conclusion, this proof-of-concept trial showed that treatment with the inhaled DNAzyme in SB010 significantly attenuated both the early-phase and late-phase asthmatic responses after allergen provocation. Further clinical studies are warranted to explore the question of whether these effects translate into clinical benefits in patients who have symptomatic, persistent asthma with a predominant Th2 phenotype.

Supported by Sterna Biologicals and by a grant (031A188) from the German Federal Ministry of Education and Research.

Disclosure forms provided by the authors are available with the full text of this article at NEJM.org.

We thank Anja Zensi, Ph.D., and Oliver Schmidt, Ph.D. (Engelhard Arzneimittel), for pharmaceutical production; Gerhard Breipohl, Ph.D., for advice on chemistry, manufacturing, and control; Gerhard Schlüter, M.D., and Claus Vogelmeier, M.D., for scientific advice; Eva Borowski, Ph.D., and Brigitte Lang (Inamed) for project management; Meike Müller, Ph.D., and Olaf Holz, Ph.D. (Fraunhofer ITEM), for laboratory analyses of biomarkers and sputum samples; Julia Roller, Gerhard Müllinger, and Rolf Krattenmacher (Activaero) for assistance with the use of the inhalation device; Annika Wolter (FGK) for statistical analysis; Gregory Morley, Ph.D., for writing support; Jens Kuhlmann and Georgios Sarigiannis (Sterna) for technical and scientific assistance; and Michaela Gnittka for assistance with the preparation of an earlier version of the manuscript.
REFERENCES

1. Global Initiative for Asthma. Global strategy for asthma management and prevention, 2014. August 12, 2014 (http:// www.ginasthma.org/local/uploads/files/ GINA_Report_2014_Aug12.pdf). 2. Bhakta NR, Woodruff PG. Human asthma phenotypes: from the clinic, to cytokines, and back again. Immunol Rev 2011;242:220-32.

3. Woodruff PG, Modrek B, Choy DF, et al. T-helper type 2-driven inflammation defines major subphenotypes of asthma. Am J Respir Crit Care Med 2009;180:38895.

4. Holgate ST. Innate and adaptive immune responses in asthma. Nat Med 2012;18:673-83.

5. Wenzel SE. Asthma phenotypes: the evolution from clinical to molecular approaches. Nat Med 2012;18:716-25.

6. Ray A, Cohn L. Th2 cells and GATA-3 in asthma: new insights into the regulation of airway inflammation. J Clin Invest 1999;104:985-93.

7. Bergqvist A, Andersson CK, Hoff- mann HJ, et al. Marked epithelial cell pathology and leukocyte paucity in persistently symptomatic severe asthma. Am J Respir Crit Care Med 2013;188:1475-7.

8. Holgate ST. Trials and tribulations in identifying new biologic treatments for asthma. Trends Immunol 2012;33:238-46. 9. Santiago FS, Khachigian LM. Nucleic acid based strategies as potential therapeutic tools: mechanistic considerations and implications to restenosis. J Mol Med (Berl) 2001;79:695-706.

10. Cho EA, Moloney FJ, Cai H, et al. Safety and tolerability of an intratumorally injected DNAzyme, Dz13, in patients with nodular basal-cell carcinoma: a phase 1 first-in-human trial (DISCOVER). Lancet 2013;381:1835-43.

11. Sel S, Wegmann M, Dicke T, et al. Effective prevention and therapy of experimental allergic asthma using a GATA3-specific DNAzyme. J Allergy Clin Immunol 2008;121(4):910.e5-916.e5.

12. Turowska A, Librizzi D, Baumgartl $N$, et al. Biodistribution of the GATA-3- specific DNAzyme hgd40 after inhalative exposure in mice, rats and dogs. Toxicol Appl Pharmacol 2013;272:365-72.

13. Dicke T, Pali-Schöll I, Kaufmann A, Bauer S, Renz H, Garn H. Absence of unspecific innate immune cell activation by GATA-3-specific DNAzymes. Nucleic Acid Ther 2012;22:117-26.

14. Fuhst R, Runge F, Buschmann J, et al. Toxicity profile of the GATA-3-specific DNAzyme hgd40 after inhalation exposure. Pulm Pharmacol Ther 2013;26:2819.

15. Homburg U, Renz H, Timmer W, et al. Safety and tolerability of a novel inhaled GATA 3 mRNA targeting DNAzyme in Th2-driven asthma. J Allergy Clin Immunol 2015 April 1 (Epub ahead of print). 16. Bateman ED, Hurd SS, Barnes PJ, et al. Global strategy for asthma management and prevention: GINA executive summary. Eur Respir J 2008;31:143-78. 17. Brand P, Beckmann H, Maas Enriquez $\mathrm{M}$, et al. Peripheral deposition of alpha1protease inhibitor using commercial in- 
halation devices. Eur Respir J 2003;22: 263-7.

18. Cockcroft DW, Murdock KY, Kirby J, Hargreave F. Prediction of airway responsiveness to allergen from skin sensitivity to allergen and airway responsiveness to histamine. Am Rev Respir Dis 1987;135:264-7. 19. Diamant Z, Gauvreau GM, Cockcroft DW, et al. Inhaled allergen bronchoprovocation tests. J Allergy Clin Immunol 2013; 132(5):1045.e6-1055.e6.

20. Gauvreau GM, Watson RM, Rerecich TJ, Baswick E, Inman MD, O’Byrne PM. Repeatability of allergen-induced airway inflammation. J Allergy Clin Immunol 1999;104:66-71.

21. Miller MR, Hankinson J, Brusasco V, et al. Standardisation of spirometry. Eur Respir J 2005;26:319-38.

22. Crapo RO, Casaburi R, Coates AL, et al. Guidelines for methacholine and exercise challenge testing-1999: this official statement of the American Thoracic Society was adopted by the ATS Board of Directors, July 1999. Am J Respir Crit Care Med 2000;161:309-29.

23. American Thoracic Society; European Respiratory Society. ATS/ERS recommendations for standardized procedures for the online and offline measurement of exhaled lower respiratory nitric oxide and nasal nitric oxide, 2005. Am J Respir Crit Care Med 2005;171:912-30.

24. Janssen O, Schaumann F, Holz O, et al. Low-dose endotoxin inhalation in healthy volunteers - a challenge model for early clinical drug development. BMC Pulm Med 2013;13:19.

25. O'Byrne PM. Allergen-induced airway inflammation and its therapeutic intervention. Allergy Asthma Immunol Res 2009;1:3-9.

26. Wenzel S, Wilbraham D, Fuller $R$, Getz EB, Longphre M. Effect of an interleukin-4 variant on late phase asthmatic response to allergen challenge in asthmat- ic patients: results of two phase 2a studies. Lancet 2007;370:1422-31.

27. Wenzel S, Ford L, Pearlman D, et al. Dupilumab in persistent asthma with elevated eosinophil levels. N Engl J Med 2013;368:2455-66.

28. Corren J, Busse W, Meltzer EO, et al. A randomized, controlled, phase 2 study of AMG 317, an IL-4Ralpha antagonist, in patients with asthma. Am J Respir Crit Care Med 2010;181:788-96.

29. Haldar P, Brightling CE, Hargadon B, et al. Mepolizumab and exacerbations of refractory eosinophilic asthma. N Engl J Med 2009;360:973-84.

30. Nair P, Pizzichini MM, Kjarsgaard M, et al. Mepolizumab for prednisonedependent asthma with sputum eosinophilia. N Engl J Med 2009;360:985-93.

31. Pavord ID, Korn S, Howarth P, et al. Mepolizumab for severe eosinophilic asthma (DREAM): a multicentre, double-blind, placebo-controlled trial. Lancet 2012;380: 651-9.

32. Corren J, Lemanske RF, Hanania NA, et al. Lebrikizumab treatment in adults with asthma. N Engl J Med 2011;365:1088-98.

33. Ingram JL, Kraft M. IL-13 in asthma and allergic disease: asthma phenotypes and targeted therapies. J Allergy Clin Immunol 2012;130:829-42.

34. Gauvreau GM, O'Byrne PM, Boulet LP, et al. Effects of an anti-TSLP antibody on allergen-induced asthmatic responses. N Engl J Med 2014;370:2102-10.

35. Petsky HL, Cates CJ, Lasserson TJ, et al. A systematic review and meta-analysis: tailoring asthma treatment on eosinophilic markers (exhaled nitric oxide or sputum eosinophils). Thorax 2012;67:199-208.

36. Vijverberg SJ, Hilvering B, Raaijmakers JA, Lammers JW, Maitland-van der Zee $\mathrm{AH}$, Koenderman L. Clinical utility of asthma biomarkers: from bench to bedside. Biologics 2013;7:199-210.

37. Wenzel S. Severe asthma: from char- acteristics to phenotypes to endotypes. Clin Exp Allergy 2012;42:650-8.

38. Brusselle GG, Maes T, Bracke KR. Eosinophils in the spotlight: eosinophilic airway inflammation in nonallergic asthma. Nat Med 2013;19:977-9.

39. Fahy JV, Fleming HE, Wong HH, et al. The effect of an anti-IgE monoclonal antibody on the early- and late-phase responses to allergen inhalation in asthmatic subjects. Am J Respir Crit Care Med 1997;155: 1828-34.

40. Cockcroft DW, Murdock KY. Comparative effects of inhaled salbutamol, sodium cromoglycate, and beclomethasone dipropionate on allergen-induced early asthmatic responses, late asthmatic responses, and increased bronchial responsiveness to histamine. J Allergy Clin Immunol 1987;79:734-40.

41. Winandy S, Brown M. No DL1 Notch ligand? GATA be a mast cell. Nat Immunol 2007;8:796-8.

42. Mjösberg J, Bernink J, Golebski K, et al. The transcription factor GATA3 is essential for the function of human type 2 innate lymphoid cells. Immunity 2012;37: 649-59.

43. Sadat MA, Kumatori A, Suzuki S, Yamaguchi Y, Tsuji Y, Nakamura M. GATA-3 represses gp91phox gene expression in eosinophil-committed HL-60-C15 cells. FEBS Lett 1998;436:390-4.

44. Gauvreau GM, Boulet LP, Postma DS, et al. Effect of low-dose ciclesonide on allergen-induced responses in subjects with mild allergic asthma. J Allergy Clin Immunol 2005;116:285-91.

45. Kent SE, Boyce M, Diamant Z, et al. The 5-lipoxygenase-activating protein inhibitor, GSK2190915, attenuates the early and late responses to inhaled allergen in mild asthma. Clin Exp Allergy 2013;43: 177-86.

Copyright $(2015$ Massachusetts Medical Society. 